\title{
Negaciones de la violencia: la vigencia de la filosofía política arendtiana ${ }^{2}$
}

\author{
Denial of the Violence: \\ the Validity of Arendtian Political Philosophy
}

\begin{abstract}
Resumen
En relación con la esencia de la política, Hannah Arendt ha mantenido una tesis crítica frente a la tradición filosófica moderna: la originalidad de su pensamiento consiste en haber postulado una idea de la política, no a partir de la relación medios/fines —en la que se equilibran e identifican poder, violencia, dominación, entre otros-, sino a partir de una necesaria distinción entre la idea de poder (con su carácter consensual y comunicativo), de la idea de dominio y de violencia. El propósito de este trabajo es dar cuenta de la riqueza, complejidad y problemática contenida en el desarrollo de su tesis sobre la violencia como negación de la política, toda vez que no se trata de una temática marginal, sino más bien de un ejercicio filosófico de gran valía y vigencia indiscutible para el estudio de la política y la sociedad del siglo XXI.
\end{abstract}

Palabras clave: violencia, poder, negación, dominación, gobierno, política, filosofía.

\begin{abstract}
According to the essence of politics, Hannah Arendt has stated a critical thesis which confronts the modern traditional philosophy: the innovation of her thought is based on the idea of politics distant from the relationship between means and ends in which are balanced and identified power, violence, discrimination, among others, but from the vital distinction between the notion of power (with its consensual and communicative character) and the idea of control and violence. The purpose of this article is to give an account of the richness, complexity, and problematic of her thesis about violence. This violence is understood as a denial of politics since it is not a marginal issue but rather a philosophical exercise of great value and undeniable validity for the study of politics and society in the XXI century.
\end{abstract}

Keywords: violence, power, denial, domination, government, politics, philosophy

Recibido el 16 de octubre de 2013 y aprobado el 5 de noviembre de 2013

1 Docente investigadora de la Universidad de la Sabana. Comunicadora Social y Periodista de la Universidad Central. Aspirante a Magister en Filosofía contemporánea de la misma Universidad. Docente catedrática, Universidad de la Sabana. Docente de la línea de Profundización Formas de Expresión en lo Público de la Universidad Central de Bogotá. Correo electrónico: lili.paredes.restrepo@gmail.com

2 Artículo resultado de investigación, derivado de tesis de Maestría en Filosofía Contemporánea, línea de investigación de la Escuela Crítica. 


\section{"La distinción firme y 0 entre poder y violencia constituye el lugar privilegiado de su pensamiento"}

Paul Ricoeur (1989)

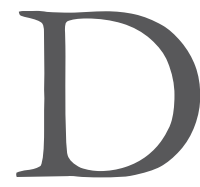
os aspectos de la tesis de Hannah Arendt sobre la relación poderviolencia serán abordados en este artículo:

1. Lo que ha tenido lugar en la tradición filosófica política moderna- y sus ecos contemporáneos- sobre los usos de las palabras que nos ocupan (violencia y poder) es que tienden a promover la sinonimia y a borrar las distinciones, afectando no sólo verbal sino políticamente la comprensión y aplicación de ambos fenómenos. El resultado es una confusión históricamente sostenida, que tiene efecto, no sólo en las tesis de los apologetas de la violencia sino también en las de los detractores de la aparición del poder en tanto que acción concertada de hombres libres.

2. En el análisis que hace Hannah Arendt sobre la violencia no oculta su clara oposición frente a la tradición en el pensamiento político moderno de tratar a la violencia como a un fenómeno por derecho propio, y gran parte de su obra está dedicada especialmente a precisar esta afirmación. Lo que constituye uno de los más importantes aportes de Arendt a la filosofía política parte de la tesis de que la violencia, lejos de ser un fenómeno por derecho propio, y muy distante del sentido que puede llegar a tener la acción (que es en sí la acción política), constituye más bien una negación permanente de toda oportunidad real de acción (en tanto encuentro entre palabra y pensamiento), impugna toda ocasión para la aparición del poder e impide la constitución de lo público. La violencia como negación es una tesis que se sustenta a partir de la revisión del tratamiento que la tradición política ha hecho sobre la violencia en relación con el poder, y las limitaciones, así como las redundancias, en las que ha derivado esta tradición.

El análisis obliga a introducir la cuestión relativa a la centralidad de la violencia en la historia; supone abordar la pregunta por la pertinencia de considerar la violencia como fenómeno que revela el núcleo de la vida histórica y política de la humanidad; lleva a interpelar a la tradición filosófica política moderna de Occidente sobre si es la violencia la clave de toda revolución y de todo cambio radical.

\section{Violencia y poder en la tradición filosófica política moderna desde Hannah Arendt:}

\section{La paradoja de la violencia como fenómeno transversal al siglo XX}

"El siglo XX tal como predijo Lenin ha resultado un siglo de guerras y revoluciones, un siglo de la violencia que se le considera su denominador común" (2010, p. 9). Con esta afirmación comienza Hannah Arendt el ensayo Sobre la Violencia, afirmación que es resultado del balance que hace la autora sobre la historia política y social el siglo XX, particularmente en lo que toca al desarrollo de capitalismo y a las formas políticas que sustentaron su fortalecimiento en Occidente. Ya en los Orígenes del Totalitarismo y en Sobre la Revolución, hasta el tratamiento particular que hace en Crisis de la República, aborda el tema de la violencia y el papel que le ha otorgado la tradición político filosófica moderna: una suerte de desplazamiento, cuando no de sustitución, del poder por la violencia. Hannah Arendt analiza el papel que ha jugado el modo como la tradición filosófica política moderna ha tratado la relación poder-violencia, en la constitución de formas de gobierno que derivaron en totalitarismos e imperialismos, así como la sustentación que desde la filosofía política moderna ha tenido este fenómeno en la construcción de la sociedad y, en particular, de la esfera pública.

Un aspecto que se destacada de su tesis consiste en el reconocimiento de un cierto carácter

Polisemia No. 16, 49 - 63. Negaciones de la violencia: la vigencia de la filosofía política arendtiana. Bogotá, ISSN: 1900-4648. Julio - diciembre de 2013 
paradójico de la violencia que, a diferencia del poder o de la fuerza, precisa — está sujeta— de herramientas y artefactos para existir y mantenerse (razón por la cual la evolución tecnológica en la fabricación de armas marca un crecimiento exponencial en la actitud bélica), y que ha alcanzado elevados grados de sofisticación, hasta convertirse en condición de posibilidad de casi toda forma de gobierno (desde el más radical totalitarismo hasta la más libre democracia). La política moderna afirma que la esencia del ejercicio de la violencia está determinado por la categoría medios-fin, cuya principal característica, aplicada a los asuntos humanos, ha sido la de que: "el fin está siempre en peligro de verse superado por los medios a los que justifica y que son necesarios para alcanzarlo" (Arendt, 2010, p. 36). Pero la evolución técnica de los medios de la violencia ha llegado al punto en que ningún objetivo político puede corresponder concebiblemente a su potencial destructivo o justificar su empleo en un conflicto. En ello radica la paradoja: la actitud bélica, que desde todos los tiempos ha oficiado como árbitro definitivo de las disputas entre hombres y naciones, ha perdido eficacia y atractivo, en tanto que son los medios los que han sustituido al fin, a todo fin, y su nivel de sofisticación ha sido de tal alcance que, al igual que el monstruo, ha comenzado a devorar tanto a sus hijos como a sus creadores. La historia del siglo XX se presenta como una coyuntura sin analogía posible con ninguna de las experiencias bélicas que le precedieron. En esta coyuntura el objetivo racional del uso de la violencia es la disuasión, no la victoria; ni siquiera es la búsqueda de equilibrio sino el mantenimiento de un statu quo, un orden inalterable que garantice la regularidad en los flujos de capital y la supervivencia del sistema político (papel que juega hoy, por ejemplo, la capacidad de desarrollo y adquisición nuclear en países como Israel o Siria). Así, si ya no es un aprestamiento para la guerra, la violencia sólo encuentra justificación sobre la base de que, más que la seguridad para la victoria, es la mejor garantía de disuasión; opera como mecanismo de control político y social, y en este contexto no tiene aplicación la tradición política filosófica del estudio de la violencia.

La paradoja de la violencia revela la irónica vigencia de su existencia hasta nuestros días: los interesados en el perfeccionamiento de los medios de destrucción han alcanzado finalmente un desarrollo técnico tal que su objetivo (la guerra) está a punto de desaparecer por mérito de los medios a su disposición; se ha roto la secuencia positiva de la Modernidad, la categoría mediosfin por la que estuvo regido todo el proyecto moderno se ha subvertido. La violencia, en tanto que medio — carácter instrumental— ha superado y sustituido el fin para el que existía y parece ser ahora un fin en sí misma; sin razón lógica, pero no irracional; sin justificación real, aunque sí política; sin legitimidad, pero sí con justificación. Es "el simple hecho de que no haya aparecido todavía en la escena política un sustituto de este árbitro final" (Arendt, 2010, p. 12) lo que justifica su vigencia y mientras siga la violencia identificada con la libertad individual, la independencia nacional, la autonomía del dominio exterior y la soberanía del Estado, es decir, la reivindicación del poder ilimitado en los asuntos internos y externos de la vida social, no parece avisarse un sustituto posible.

\section{La violencia y el poder en la tradición moderna}

Un juicioso seguimiento que hace Arendt a la tradición política moderna, a propósito del tema del poder en relación con la violencia, lleva a descubrir que existe un acuerdo entre una buena parte de los teóricos políticos, tanto de la izquierda como de la derecha, según el cual la violencia no es sino la más flagrante manifestación de poder. ${ }^{3}$

3 Arendt trae a colación afirmaciones como la de Writht Mills a propósito de que el último género de poder es la violencia, haciéndose eco de la definición del Estado de Max Weber como el dominio de los hombres sobre los hombres basado en los medios de la violencia legitimada. Para más información consultar The Power Elite (1956). Max Weber consistente con la observación de Trotsky: "Todo Estado está basado en la violencia". 
Esta equiparación resulta para Arendt confusa y nociva, toda vez que hacer coincidir el poder político con la organización de la violencia sólo tendría sentido si se acepta incondicionalmente la idea marxista del Estado como instrumento de opresión de la clase dominante. Arendt interpela profundamente esta equiparación a propósito de la existencia futura, no sólo del Estado sino de toda organización política, cuando el cuerpo político, sus leyes e instituciones no sean simplemente superestructuras coactivas o manifestaciones secundarias de fuerzas subyacentes; $¿$ es posible entonces afirmar que el final de la actividad bélica conlleva al final de los estados y de otras organizaciones humanas? Más aún, ¿significa la desaparición de la violencia el final del poder?

\section{Tradiciones político-filosóficas sobre la relación poder-violencia}

De acuerdo con el análisis histórico que hace la autora, es la tradición hebreo-cristiana la que hizo un significativo aporte al fortalecimiento y confirmación del vocabulario del que se ha nutrido el discurso sobre poder y violencia durante la Edad Media, y favoreció con ello el mantenimiento de regímenes monárquicos, con la anexión del imperativo concepto de ley. Esta idea, que no fue producto de la creatividad de políticos realistas, es más bien el resultado de una generalización apriorística de los mandamientos de Dios, según la cual la simple relación mando-obediencia sería suficiente para identificar la esencia de la ley.

Sin embargo, la lectura que hicieron los revolucionarios del siglo XVIII al desentrañar los archivos de las antiguas civilizaciones, en los que la ciudad-estado ateniense plantea su constitución como una isonomía, o cuando los romanos enunciaron la civitas como su forma de gobierno, tenían en mente un concepto del poder y de la ley cuya esencia no descansaba sobre la relación mando-obediencia, con este espíritu se constituyó una forma de gobierno - República-, en la que el dominio fuera de la ley, teniendo como pilar el poder del pueblo, que pondría fin al dominio del hombre sobre el hombre, al que se consideró un gobierno adecuado para esclavos. Pero este esfuerzo no pudo escapar al peso de la obediencia: obediencia a las leyes en lugar de obediencia a los hombres.

Lo que dota de sentido opuesto la relación mando-obediencia de la tradición anterior, es que en esta forma de gobierno la obediencia se traduce en apoyo a las leyes a las que la ciudadanía ha otorgado su consentimiento. Aunque semejante apoyo nunca es indiscutible y, por lo que a su formalidad se refiere, jamás puede comparase con la indiscutible obediencia que puede exigir un acto de violencia - la obediencia que consigue un hombre cuando somete a otro con la ayuda de un arma-, es el apoyo del pueblo el que presta poder a las instituciones de un país y este apoyo no es nada más que la prolongación del asentimiento que, para empezar, determinó la existencia de las leyes. Bajo estas condiciones, en un gobierno representativo el pueblo domina a quienes lo gobiernan y todas las instituciones políticas son manifestaciones y materializaciones de ese poder; se petrifican y decaen tan pronto como el poder vivo del pueblo deja de apoyarlas. Esto es exactamente lo que Madison quiere significar con la tesis de que todos los gobiernos descansan en la opinión, afirmación no menos cierta para las diferentes formas de monarquía como para las democracias. ${ }^{4} \mathrm{El}$ poder, en la tradición política moderna, es un instrumento de mando y debe su existencia al instinto de dominación. ${ }^{5}$

4 Sin embargo, la fuerza de la opinión —el poder del gobierno - depende del número: se halla en proporción con el número de los que están con él asociados y la tiranía, como descubrió Montesquieu, es por eso la más violenta y menos poderosa de las formas de gobierno.

5 Vale recordar la tesis de Sartre sobre la violencia cuando afirma que un hombre se siente más hombre cuando se impone a sí mismo y convierte a otros en instrumentos de su voluntad, lo que proporciona incomparable placer. El poder -dice Voltaireconsiste en hacer que otros actúen como yo decida; está presente cuando yo tengo la posibilidad de afirmar mi propia 
En la revisión que hace la autora de la tradición filosófico política moderna encuentra pocas voces disidentes de esta idea de la relación poder-violencia. ${ }^{6}$

Para el siglo XIX y principios del XX, buena parte del pensamiento político occidental elabora una formulación pragmática en la filosofía hegeliana, y también marxista, con respecto a la trascendencia de la violencia en el progreso y en el cambio histórico. A la idea hegeliana de la justificación histórica de la violencia, desarrollada por Sorel, Pareto y Sartre, Hannah Arendt se opone radicalmente, así como a las implicaciones que su adopción ha traído en la reflexión sobre la relación poder-violencia. En lo que toca al poder, Arendt está más cercana a la idea hobbnesiana de que la violencia se produce al margen de la política y del poder propiamente dichos, pero la comprensión arendtiana de la esencia del poder es claramente distinta.

Sin embargo, estas ideas de poder tienen un asidero histórico común: no sólo se derivan de la antigua noción de poder absoluto que acompañó a la aparición del soberano Estado-nación europeo, (tesis de Jean Bodin en la Francia siglo XVI y Thomas Hobbes en la Inglaterra del siglo XVII), sino que armonizan también con los tér- minos empleados desde la antigüedad griega para definir las formas de gobierno como el dominio del hombre sobre el hombre —así de uno o de unos pocos en la monarquía y en la oligarquía; de los mejores o de muchos en la aristocracia y en la democracia-.

A la carrera que ha hecho esta tradición de la categoría de dominio a lo largo del siglo XX pertenece la que Arendt identifica quizá como la más aterradora forma de dominio: la burocracia o dominio de nadie, un complejo sistema de oficinas en donde no cabe hacer responsables a los hombres, ni a uno ni a los mejores, ni a pocos ni a muchos. En palabras de Arendt, si, conforme el pensamiento político tradicional, se identifica a la tiranía como el gobierno que no está obligado a dar cuenta de sí mismo, el dominio de nadie es claramente el más tiránico de todos, pues no existe precisamente nadie al que pueda preguntarse por lo que está haciendo.

Finalmente, apuestas científicas y filosóficas más contemporáneas respecto de la naturaleza del hombre han reforzado aún más estas tradiciones filosóficas y políticas sobre la relación poderviolencia-dominación. Nuevas teorías científicas sobre un cierto instinto innato de dominación y de una innata agresividad del animal bumano han sido anticipadas por afirmaciones filosóficas similares. ${ }^{7}$

voluntad contra la resistencia de los demás, plantea Max Weber; una definición más contemporánea (Clauswitz) define de la guerra como un acto de violencia para obligar al oponente a hacer lo que queremos que haga; es mandar y ser obedecido: sin lo cual no hay poder, y no precisa de ningún otro atributo para existir [...] La cosa sin la cual no puede ser: que la esencia es el mando, afirma Jouvenel (Arendt, 2010, p. 51).

6 La noción de R.M. Mclver respecto a que el poder coactivo es un criterio del Estado pero no constituye su esencia; es cierto que no existe Estado allí donde no hay una fuerza abrumadora, pero que el ejercicio de la fuerza no hace un Estado. Recalca así mismo la importancia de la distinción que hace Alexandre Passerin dEntrèves entre la esencia del poder y la eficacia del mando, porque le permite señalar entonces que no habría poder más grande que el que emana del cañón de un arma y la dificultad que encarna decidir en qué forma difiere la orden dada por un policía de la orden dada por un pistolero.

7 De acuerdo con Jhon Stuart Mill, la primera lección civilizadora es la obediencia, con sus dos estadios de inclinación: deseo de ejercer poder sobre los demás y aversión a que el poder sea ejercido sobre uno mismo. La lógica simple llevaría a evidenciar que todo instinto de sumisión, un ardiente deseo de obedecer y de ser dominado por otro, es tan preponderante en la psicología humana como el deseo de poder y, políticamente, resulta quizá más relevante. El antiguo adagio "cuan apto es para mandar quien puede también obedecer" puede detonar una verdad psicológica: la de que la voluntad de poder y la voluntad de sumisión se hallan interconectadas. La pronta sumisión a la tiranía no está de manera alguna siempre causada por una extrema pasividad. Recíprocamente, una fuerte aversión a obedecer viene acompañada a menudo por una aversión a dominar y mandar. 
Ante este corolario tradicional es imperativo asumir una postura; es necesario decidir en qué sentido puede el poder distinguirse de la violencia, escrutar cómo el hecho de utilizar la violencia conforme a la ley cambia la calidad de la misma y cómo esta calidad afecta las relaciones humanas, suponiendo que la violencia, por el simple hecho de ser calificada, deja de ser violencia; si el poder puede ser una violencia calificada o institucionalizada, un tipo de violencia mitigada; o si por el contrario se trata de fenómenos colaterales pero no idénticos ni derivables y esto es lo que hace Hannah Arendt.

\section{Repensar conceptos claves}

El desarrollo de la tesis arendtiana sostiene que antiguas verdades acerca de la relación entre la guerra y la política, la violencia y el poder, resultan inaplicables en el siglo XX. Los modos de abordar la violencia en los registros históricos y políticos de Occidente evidencian que, si bien ningún estudioso de la historia y la política pondría en duda el capital papel que ha desempeñado la violencia en el arbitraje de los asuntos humanos, al mismo tiempo ha sido singularizada muy escasas veces para su consideración y comprensión; se ha priorizado el estudio del método así como del instrumento, pero no a la violencia como tal. Esta actitud revela el talante con que la tradición ha estudiado la violencia y su arbitrariedad; cualquier emprendimiento en búsqueda del sentido de ésta en los registros del pasado la encontrará como un hecho marginal.

Tanto si es Clausewitz, denominando la guerra la continuación de la política por otros medios, como si es Engels, definiendo la violencia como el acelerador del desarrollo económico, siempre se presta relieve a la continuidad política o económica, a la continuidad del proceso que permanece determinado por aquello que precedió a la acción violenta (Arendt, 2005, p.17).

Priorizar el potencial bélico como la principal fuerza estructuradora de la sociedad, mantener que los sistemas económicos, las filosofías políticas y los corpora juris sirven y extienden el sistema bélico y no al revés, concluir que la guerra en sí misma es el sistema social básico, dentro del cual chocan o conspiran otros diferentes modos de organización humana, resulta tan criticable como afirmar que la paz es la continuación de la guerra por otros medios.

Sabido es que el desarrollo y sofisticación de la industria armamentística ha alcanzado un punto muy alto en términos de eficacia y economía: unas pocas armas en unos segundos pueden barrer todas las demás fuentes de poder nacional; grandes adelantos en el diseño de armas biológicas que permitirían a un pequeño grupo de individuos alterar el equilibrio estratégico. La cantidad de violencia a disposición de cualquier país bien puede no ser pronto una indicación fiable de la potencia del país o una fiable garantía contra la destrucción a manos de otro, sustancialmente más pequeño y más débil. Este panorama evidencia uno de los principios olvidados o deliberadamente ignorados de la filosofía política moderna: el de que el poder no puede ser medido en términos de riqueza o de potencial bélico, que una abundancia de riqueza y de material bélico a disposición puede (y lo hace) erosionar el poder; que la violencia que desata esta potencia es particularmente peligrosa para el poder porque no sólo lo destruye sino que le niega cualquier posibilidad de aparecer de nuevo.

\section{Violencia y poder: distinciones necesarias}

Resulta cuando menos frustrante el balance que arroja la revisión que hace Arendt sobre el uso de la terminología relativa a la relación poder-violencia, en la medida en que no hace distinciones claras respecto a potencia, fuerza, autoridad, las cuales se refieren a fenómenos distintos aunque coexistentes y colaterales a la relación. No resulta ilógico suponer que se refieren a propiedades diferentes y que su significado debería por eso ser cuidadosamente examinado. Para Arendt de lo que se trata no es simplemente de una cuestión de habla descuidada: lo que resulta de la interpretación respecto al 
empleo de estas palabras no es sólo una cuestión de gramática lógica, sino de perspectiva histórica. Emplearlas como sinónimos no sólo indica una cierta sordera a los significados lingüísticos, lo cual sería suficientemente complejo, sino que ha traído como consecuencia un tipo de ceguera frente a las realidades a las que corresponden. Lo que esconde esta aparente confusión es una profunda convicción política que ha puesto la teoría al servicio del mantenimiento de cierto statu quo; todos los términos se reducen a indicar los medios mediante los cuales manda el que manda; poder, potencia, fuerza, autoridad y violencia no serían más que palabras para indicar los medios por los que el hombre domina al hombre; se emplean como sinónimos porque poseen la misma función. Tras la aparente confusión existe una firme convicción a cuya luz todas las distinciones serían, en el mejor de los casos, de importancia menor: la convicción de que la más crucial cuestión política es, y ha sido siempre, la de ¿quién manda a quién?, cuya aplicación no se ha limitado al ejercicio de dominio en sí mismo, sino que se ha traducido en la negación del poder mismo; el imperativo de la violencia, en si afán por sustituir al poder, no sólo lo ha desplazado sino que le ha negado su posibilidad de aparición.

En tal sentido, resulta de capital importancia hacer explícitos los matices sustanciales, relaciones y oposiciones de cada uno de los términos comprometidos en este escenario.

En su sentido más habitual, el poder se refiere a la capacidad de algo o de alguien para producir determinado efectos, para afectar a otros y sus circunstancias. Cuando se habla de poder social o poder político, que es el situs del poder propiamente dicho, se advierte sobre la posibilidad del hombre de actuar en lo público. Sin embargo, frecuentemente esta acción se interpreta como ejercicio de poder del hombre sobre el hombre, una suerte de mediación de la relación entre los individuos: entonces se habla de poder como dominación, determinación, coacción. El poder como coacción, que más sería una forma de mantener el poder, es un fenómeno capital, bien por la difusión, que le ha valido un claro posicionamiento en el registro de la tradición del pensamiento político, bien por su omnipresencia y transversalidad en la historia, bien por su centralidad. Ratificar la afirmación de Max Webber de que el poder político tiene el monopolio de la violencia equivale a afirmar que la violencia es su medio más específico y tendencialmente exclusivo, y que el recurso de la coacción para sustentar el poder ha sido un rasgo característico del poder político. En este sentido, dominio y violencia serían en unos casos instrumentos, en otros casos expresiones del poder político. La tesis arendtiana sobre el poder se propone romper esta compacidad.

Radicalmente opuesta a esta idea de poder, Arendt coincide en un único punto de encuentro con esta perspectiva: el poder es una relación entre hombres. "El poder corresponde a la capacidad humana, no simplemente para actuar, sino para actuar concertadamente. Éste nunca es propiedad de un individuo; pertenece a un grupo y sigue existiendo mientras que el grupo se mantenga unido (Arendt, 2005, p. 60). Cuando se hace referencia a que alguien está en el poder se refiere realmente a que ese alguien tiene el poder de cierto número de personas para actuar en su nombre. En el momento en que el grupo, del que el poder se ha originado, desaparece, todo poder también desaparece. Tiene una vocación colectiva y en ello radica la posibilidad de su existencia y conservación. La clave es el consentimiento, la afirmación plural, el asentimiento colectivo; sin el consentimiento del grupo, un hombre pierde todo poder y ni lo público ni la política tienen lugar, toda vez que el poder: "es lo que mantiene la existencia de la esfera pública, el potencial espacio de la aparición de los hombres que actúan y hablan entre si’" (Arendt, 2005, p. 223). El poder (actuar en concertación) es condición de posibilidad del escenario político, del espacio de aparición de la comunidad de hombres libres. Inclusive la tiranía o cualquiera de los totalitarismos contemporáneos requieren cierto consenso, al menos el de los hombres que, aunque no convencidos o interesados, sí dispuestos a mantener el aparato político administrativo bajo el cual operan. 
Aunque fuese posible concebir todos los instrumentos de la violencia en manos de un solo hombre, éste carecería de poder, y por ende, de posibilidades políticas. El poder verdadero, el que procede de la acción concertada sostenida no tiene rival; nada ni nadie puede dominarlo o negarlo; ninguna violencia puede sustituirlo. La fecundidad y calidad del poder resisten la fuerza y la violencia, por intensos y demoledores que sean sus instrumentos. Esta concepción la ve claramente Arendt cuando afirma que:

La rebelión popular contra gobernantes materialmente fuertes puede engendrar un poder casi irresistible incluso si se renuncia al uso de la violencia frente a fuerzas muy superiores en medios materiales. Llamar a esto resistencia pasiva es una idea irónica, ya que se trata de una de las más activas y eficaces formas de acción que se haya proyectado, debido a que no se le puede hacer frente con la lucha, de la que resulta la derrota o la victoria, sino únicamente con la matanza masiva en la que incluso el vencedor sale derrotado, ya que nadie puede gobernar sobre los muertos (2005, p. 223).

$\mathrm{Y}$ al margen de la fragilidad y/o ingenuidad que pueda alegársele a esta concepción arendtiana del poder, de cara al determinismo histórico que ha tenido la violencia en la tradición políticofilosófica moderna, lo que valoriza el pensamiento de Arendt es que existe algo político, relativo a la pluralidad de los hombres, no violento, capaz de acabar con la violencia: y esto contrario a la violencia no es la no-violencia (como se le ha llamado en algunas experiencias históricas con las que la autora puede tener cierta cercanía, como la resistencia de Gandhi en la India), sino el poder.

El poder escapa al esquema tradicional medios-fines; no responde al análisis causal (¿por qué el poder?) ni al objetivismo determinante (¿para qué el poder?), es prioritario respecto a la estrategia. Un ejercicio de poder no se circunscribe a la consecución de un consenso con miras a alcanzar objetivos previamente fijados; la esencia del consenso y el acuerdo es ser fines en sí mismos, atendidos y entendidos como tales por todos los implicados en la acción. El poder entonces es un fin en sí mismo, cuya vocación exige la protección y la promoción de la libertad, en tanto es principio de algo nuevo (razón de ser de la acción politica).

El poder es cosa de hombres que piensan y actúan, pero sobre todo hablan, interpelan, debaten; hombres con rostro y lenguaje. Tiene un carácter eminentemente comunicativo. El poder no tiene nada de impersonal, no es propiedad de estructuras ni de sistemas, es -en sentido nietzscheano- bumano, demasiado bumano. De ahí la crítica al fenómeno contemporáneo de la exacerbada burocratización (lo que Arendt identifica con el dominio de nadie) que encarna la impersonalidad, el anonimato, la superficialidad, el peligro inminente de la parálisis que mantiene los statu quo. La inercia patológica a la que conduce la burocratización social y política sienta las bases para la emergencia de la violencia propia del totalitarismo. En ausencia de individuos y en presencia de complejas estructuras impersonales, nada ni nadie es responsable de nada ni de nadie, lo que conduce inevitablemente a la disolución de la política como palabra y la consecuente pérdida de la responsabilidad del juicio.

En este sentido, conceptualmente hablando, el poder corresponde a la esencia de todos los gobiernos [en tanto encuentro entre hombres], pero no así la violencia. La violencia es, por naturaleza, instrumental; como todos los medios siempre precisa de una guía y una justificación hasta lograr el fin que persigue. Y lo que necesita justificación por algo no puede ser la esencia de nada. El poder pertenece a la misma categoría que la paz; el fin de la guerra es la paz o la victoria, pero para la pregunta ¿cuál es el fin de la paz?, no hay respuesta. La paz, como el poder, es un absoluto. No significa con esto que se niegue el hecho de que los gobiernos apliquen políticas y empleen su poder para lograr objetivos prescritos. Pero la esencia del poder en sí mismo antecede y resiste a todos los objetos, de forma que éste, lejos de constituirse en el medio para un fin, es realmente lo que le permite a un grupo de personas pensar y actuar en términos de categorías medios-fin; es la condición de posibilidad de estar y hacer en el mundo en una relación medios-fines. 
El gobierno es esencialmente poder organizado e institucionalizado. Por tal razón, la pregunta por ¿cuál es el fin del gobierno?, así formulada, carece de sentido para Arendt. ${ }^{8}$

El poder, diferente de la violencia, no necesita justificación (siendo como es inherente a la verdadera existencia de las comunidades políticas); lo que precisa es legitimidad, cuyo empleo como sinónimo no es menos desorientador y perturbador que la ecuación poder $=$ violencia. El poder deriva su legitimidad del encuentro inicial, de la concertación primera, más que de cualquier acción que pueda seguir a ésta. La legitimidad, cuando se ve desafiada, apela al pasado, al encuentro original, mientras que la justificación se refiere a un fin que se encuentra en el futuro. La violencia, a diferencia del poder, puede ser justificable pero nunca será legítima. Su justificación pierde plausibilidad cuanto más se aleja en el futuro propuesto. Nadie discute el uso de la violencia en defensa propia porque el peligro no sólo resulta claro sino que es actual y el fin que justifica los medios es inmediato. En ello radica lo tentador del uso de la violencia y el desplazamiento del poder. Cada reducción de poder es una abierta invitación a la violencia, aunque sólo sea por el hecho de que a quienes tienen el poder, y sienten que se desliza de sus manos, sea el gobierno o los gobernados, siempre les ha sido difícil resistir a la tentación de sustituirlo por la violencia.

Cuando se habla de un hombre poderoso o de una poderosa personalidad se emplea la palabra poder metafóricamente; a lo que se hace referencia sin metáfora es la potencia que designa inequívocamente a algo en una entidad singular, individual; es la propiedad inherente a un objeto y pertenece a su carácter, que puede demostrarse a sí mismo en relación con otras cosas o con otras personas, pero es esencialmente independiente de ellos. La potencia del más fuerte individuo puede ser siempre superada por las de muchos que a menudo se combinarán, sin más propósito que el de arruinar la potencia precisamente por obra de su independencia peculiar (Arendt, 2010, p. 61). No así con la fuerza, frecuentemente utilizada en el discurso cotidiano como sinónimo de violencia, -especialmente si esa violencia sirve como medio de coacción-, concepto que Arendt reserva en su lenguaje terminológico a la descripción de las dinámicas de las fuerzas de la naturaleza o a lo que la autora denomina fuerza de las circunstancias, esto es, usar el concepto para indicar la energía liberada por movimientos físicos o sociales.

La autoridad, en cambio, merece un análisis especial en la filosofía política arendtiana. Resulta indicador del carácter esquivo de este fenómeno el hecho de que se le otorgue una doble residencia: la autoridad puede ser atribuida a las personas - toda vez que existe algo como autoridad personal, por ejemplo, en la relación entre padre e hijo o entre profesor y alumno-, así como a las instituciones - como el Senado o las distintas jerarquías de la Iglesia-; su valor y sentido descansa sobre el irrefutable reconocimiento por parte de aquellos a quienes se les pide obediencia; no precisa ni de la coacción ni de persuasión aunque demanda cierto sentido de gradación o de jerarquía para sostenerse; se afirma sobre la relación subordinada entre individuos, al tiempo que lleva dentro de sí la posibilidad de la subversión, de forma que: "un padre puede perder su autoridad, bien por golpear a un hijo o bien por ponerse a discutir con él, es decir, bien por comportarse con él como un tirano o bien por tratarle como a un igual" (Arendt, 2005, p. 75). En este sentido, la persuasión y la autoridad resultan incompatibles, en tanto la última presupone igualdad y opera mediante la competencia de la argumentación. Frente al uso de argumentos, la autoridad entra en un estado de latencia; y ante el orden igualitario de la persuasión, sostenido por la argumentación, se alza el orden autoritario

8 La respuesta sería, lógicamente política, permitir a los hombres vivir juntos o bien peligrosamente utópica, promover la felicidad o realizar una sociedad sin clases o cualquier otro ideal político que, si se examinara seriamente, lastimosamente se advertiría que sólo podría conducir a algún tipo de tiranía. 
soportado en la jerarquía. La relación autoritaria entre el que manda y el que obedece no se apoya en una razón común ni en el poder del primero; lo que tienen en común es la jerarquía misma, cuya pertinencia y legitimidad reconocen ambos y en la que ambos ocupan un puesto predeterminado y estable. La autoridad se distingue tanto de la coacción por la fuerza como de la persuasión por argumentos. El ser portador de la autoridad exige la actitud mediadora del respeto, bien para la persona investida de ella, bien para la entidad que la ostenta. Frágil como la mayoría de fenómenos que afirman la política, el mayor enemigo de la autoridad es el desprecio y el más seguro medio de minarla es la burla. Allí donde las normas, las leyes y los acuerdos son vulnerados por los dominados siempre habrá dominantes que han tolerado o permitido la mofa, la sátira e incluso la ironía de sus dominados, han perdido su respeto y así han perdido también la autoridad.

Cuando la autoridad abandona, el poder aparece. Cuando el poder entra, sustentado en el mayoritario número (mayoría de dominados, respecto de dominantes), se recurre a la violencia para romper este poder, (es el caso de las revueltas protagonizadas por movimientos campesinos, obreros o estudiantes). No es distinto cuando se trata de autoridad personal o institucional; cuando las instituciones como el Estado, la Iglesia, la Familia o la Universidad, que están basadas en la autoridad - y por tanto precisan respeto-, la pierden, abren la puerta a la aparición de un nuevo poder, un poder alternativo al institucional que condiciona la utilización de la violencia para ser restringido. Por esto resulta tan difícil tratar con el poder en términos no violentos. Tales instituciones han recurrido a la protección de la violencia institucionalizada (Policía, Ejército) a lo largo de la historia, de la misma forma que lo hizo la Iglesia Católica antes de que el proceso de secularización la obligara a basarse solamente en la autoridad. Distinto que el poder, las crisis de autoridad que han conocido las instituciones políticas tradicionales - incluida la Iglesia, única institución secular todavía basada en la autoridad-, quizá pueda atribuirse a la explosión del átomo "obediencia", cuya estabilidad, basada como lo plantea la tradición cristiana, era supuestamente eterna.

Pero aún a la sombra de estas distinciones, la autoridad es el fenómeno más frecuentemente confundido con el poder sin poder afirmar que sean lo mismo, dado que ambos parecen ser condiciones de poder para la existencia de una sociedad institucionalizada; "la autoridad siempre demanda obediencia y por este motivo es corriente que se la confunda con cierta forma de poder o de violencia" (Arendt, 1996, p. 102). El poder institucionalizado en comunidades organizadas aparece a menudo bajo la apariencia de autoridad, exigiendo un reconocimiento instantáneo e indiscutible; y lo que ha demostrado la historia es que ninguna sociedad podría funcionar sin él.

Es preciso reconocer que resulta tentador concebir el poder en términos de mando y obediencia e igualar así al poder con la violencia. Como en las relaciones exteriores y en las cuestiones internas aparece la violencia como último recurso para mantener intacta la estructura del poder frente a retos individuales —así el enemigo extranjero, así el delincuente nativo-, parece como si la violencia fuese prerrequisito del poder y el poder nada más que una fachada, un guante de terciopelo que, o bien oculta una mano de hierro o bien resulta pertenecer a un tigre de papel.

La violencia, distinta a todos estos fenómenos, se distingue por su carácter puramente instrumental. Desde una perspectiva arendtiana, la violencia está más cercana a la potencia, dado que los instrumentos de la violencia, como todas las demás herramientas, son concebidos y empleados para multiplicar la potencia natural, hasta que en la última fase de su desarrollo puedan sustituirla. No dependiente del número o de la suma de las opiniones, sino de los instrumentos y del aparato institucional al que sostienen. La violencia aumenta y multiplica la potencia humana, de modo que aquellos que se oponen a la violencia con el simple poder inevitablemente descubrirán que se enfrentan no sólo con hombres sino con artefactos de los hombres, cuya inhumanidad y eficacia destructiva aumenta en proporción a la distancia que separa a los oponentes. 
La violencia, siendo por su naturaleza un instrumento, es racional hasta el punto en que resulte efectiva para alcanzar el fin que deba justificarla. Y teniendo en cuenta que no le es dado al hombre conocer con certeza los resultados puntales de sus actos, la violencia seguirá siendo racional sólo mientras esté a la postre de fines a corto plazo. La violencia, en sí misma, no promueve causas; pero está al servicio de dramatizar ofensas, de hacerlas más seductoras a la percepción sensible, de exacerbar los sentidos, y sirve para exhibirlas en la palestra pública. La violencia es, entonces, más un arma de reforma que de revolución. Entonces, el peligro de la violencia es siempre el de que los medios superen al fin. Así, si los fines no se alcanzan rápidamente, el resultado no será sólo la derrota, sino la irreversible introducción de la práctica de la violencia en todo el cuerpo político y su institucionalización. La actitud violenta es definitiva y resulta improbable que, en caso de derrota, se dé un retorno al estado original, al orden inicial de las cosas. La práctica de la violencia, como todo acto, cambia el mundo, pero el cambio más probable será el principio de un mundo más violento. La sustitución del poder por la violencia puede significar la victoria a expensas del mayor costo humano posible, porque no sólo lo pagan los vencidos, también lo pagan los vencedores en términos de su propio poder.

Lo que registra la historia de la humanidad es que no ha existido un gobierno exclusivamente basado en los medios de la violencia. Incluso el dirigente totalitario, cuyo principal instrumento de dominio es la tortura, necesita un poder básico institucionalizado, ${ }^{9}$ aunque soportado en la administración y ejercicio de los instrumentos de la violencia. Incluso el más despótico dominio conocido, el del amo sobre los esclavos, que siempre le superarán en número, no descansa exclusivamente en la superioridad de medios de coacción como tales, sino en una superior organización del poder, en la solidaridad organizada de los amos. Un solo hombre sin el apoyo de los otros jamás tiene suficiente poder como para emplear la violencia con éxito.

Para Arendt, la forma más extrema de poder es la de todos contra uno y la forma más extrema de violencia es la de uno contra todos. Y esta última nunca es posible sin instrumentos. Es políticamente aceptada la afirmación de que una minoría, pequeña y desarmada puede lograr con éxito y por medio de la violencia - explícita (gritando o promoviendo un escándalo) o simbólica (no participando) - interrumpir la acción política y, por lo tanto, la aparición del poder. Sin embargo, tiene lugar algo mucho más serio para Hannah Arendt: lo que permite la emergencia de la violencia es la decisión negativa de la mayoría a emplear su poder y a imponerse sobre los que suspenden la acción. Es el revés de la tesis moderna: no es la eficacia en sí misma de los instrumentos — violentos - lo que inclina la balanza en favor de la violencia, sino la renuncia de la mayoría a actuar concertadamente para dejar aparecer el poder; éste no aparece porque nadie deliberadamente nadie, desea actuar, hacer algo a favor de la acción que tenía lugar en primera instancia. Lo cual prueba sólo que una minoría puede tener un poder potencial mucho más grande del que cabría suponer limitándose a contar cabezas en sondeos de opinión. La mayoría simplemente observadora, entretenida por el espectáculo de pugna y gritos entre la minoría violenta institucionalizada y la resistencia, es aliada latente de la minoría y patrocinadora de la violencia imperante.

9 En un contexto de violencia contra violencia la superioridad del gobierno ha sido siempre absoluta. Pero esta superioridad está circunscrita a la permanencia intacta de la estructura de poder del gobierno —es decir, mientras que las órdenes sean obedecidas y la institución violenta (Ejército o las fuerzas de policía) estén dispuestos a empelar sus armas-. Allí donde las órdenes no son ya obedecidas, los medios de violencia pierden utilidad, básicamente porque el carácter de esta obediencia no está articulada por la relación tradicional mando-obediencia sino por la opinión, y por el número de quienes la comparten. Todo depende del poder que haya tras la violencia. Lo cierto es que allí donde el poder se ha desintegrado, la revolución se torna posible. 
El discurso político contemporáneo afirma que la impotencia engendra violencia, afirmación que puede resultar cierta desde el punto de vista psicológico de quien posee potencia moral o física para propiciar la aparición de poder, pero que encuentra minado su ejercicio. Políticamente hablando, lo cierto es que la pérdida de poder se convierte en una tentación para relevarlo por la violencia y que la violencia en sí deriva en impotencia. Los medios de destrucción determinan el fin, que será en últimas, la destrucción de todo poder, incluido el propio. ${ }^{10}$

Políticamente hablando, es insuficiente decir que poder y violencia son la misma cosa. El poder y la violencia son más bien opuestos: donde uno domina falta absolutamente el otro (Arendt, 2005, p. 77). La violencia aparece donde el poder está en riesgo, y en su propio impulso de tomar su lugar, acaba por hacer desaparecer el poder. La violencia puede destruir el poder, pero es absolutamente incapaz de crearlo.

\section{Naturaleza, racionalidad y causas de la violencia}

Los apologetas de la violencia han tendido a ver en ella algo inherente a la vida misma y un medio para asegurarla; de aquí procedería su indiscutible justificación: la violencia es expresión de la lucha por la propia vida, individual y colectiva. Se trataría entonces de una justificación naturalista de la violencia, que para Arendt carece de todo valor político.

Para saber que la gente luchará por su patria, no creo que necesitásemos conocer los instintos del "territorialismo de grupo" de las hormigas, los peces y los monos; y para conocer que el hacinamiento origina irritación y agresividad, no creo que necesitásemos experimentar con ratas. Habría bastado con pasar un día en los barrios miserables de cualquier gran ciudad (Arendt, 2010, p. 80).

Parece categórico en la tradición del pensamiento occidental aceptar que el hombre toma sus normas de conducta de otras especies animales, en la medida en que se le define como perteneciente al reino animal, la consideración del comportamiento violento como una reacción natural. Un carácter violento, en tanto impulso instintivo, sería equiparable a la función que, en el marco de la naturaleza, cumplen otros instintos en el proceso de vida y conservación de las especies y de los individuos, con la diferencia de que dichos instintos son activados por apremiantes necesidades corporales y estímulos externos, mientras que el instinto violento es independiente de provocación y tal falta de incitación conduce necesariamente la represión del instinto y acumulación de energía, cuya eventual explosión es peligrosa. De acuerdo con esta interpretación, la violencia sin provocación resulta entonces natural: si ha perdido su explicación, básicamente su función de auto-conservación, se torna irracional y ésta es, aparentemente, la causa por la que los hombres pueden ser más violento que los otros animales. "Nada, en mi opinión, podría ser teóricamente más peligroso que la tradición de pensamiento orgánico en cuestiones políticas, por la que el poder y la violencia son interpretados en términos biológicos" (Arendt, 1996, p. 101).

La justificación biológica de la violencia, tan en boga en el siglo XX, está íntimamente vinculada con los aspectos más perjudiciales de las

10 El estado que mejor evidencia el factor autoderrotante del triunfo de la violencia lo recoge Arendt en Los Orígenes del Totalitarismo, donde ilustra el ejercicio del terror para mantener una dominación. El terror no es lo mismo que la violencia; es la forma de gobierno que llega a existir cuando la violencia, tras haber destruido todo poder, no abdica, sino que por el contrario sigue ejerciendo un completo control. El terror es una variante de la violencia (dominio donde todo poder ha sido anulado). Aun siendo diversos los elementos constitutivos del totalitarismo (partido único, sociedad masificada, ideología totalitaria, entre otros), el terror es, tal como muestra Arendt en Los Orígenes del Totalitarismo, uno de los más importantes, sino el más específico y definitivo. La violencia que adopta la forma de terror totalitario elimina la comunicación entre los hombres, la acción común, la misma vida interior y la identidad y personalidad de los que somete. Sobre este hecho sustenta Arendt, el terror como el extremo paradigmático de lo que representa la negación de la existencia humana en cuanto a existencia política.

Polisemia No. 16, 49 - 63. Negaciones de la violencia: la vigencia de la filosofía política arendtiana. Bogotá, ISSN: 1900-4648. Julio - diciembre de 2013 
más antiguas tradiciones de pensamiento político. Según el concepto tradicional de poder identificado con la violencia, éste tiene un carácter expansionista por naturaleza; está preñado de un impulso, de una voluntad interna de crecimiento y ese instinto es lo que le confiere la capacidad creativa. Si es natural el proceso de la vida de dilatación y contracción, aplicado a los asuntos humanos el poder puede sustentarse a sí mismo sólo a través del ensanchamiento, de la propagación, so pena de reducirse y desaparecer.

Las metáforas orgánicas que saturan la reflexión sobre la violencia — la noción de una sociedad enferma de la que son síntoma los conflictos, como la fiebre es síntoma de la enfermedad-, sólo pueden ser reproductores de violencia. Este énfasis en el medio, en el terreno (la biología, la naturaleza, el proceso de la vida) ha distraído, cuando no desplazado por completo, el énfasis en el objeto (la violencia). Razón por la que Arendt plantea que mientras se hable no en términos políticos, sino biológicos, los glorificadores de la violencia pueden recurrir al innegable hecho de que en el dominio de la naturaleza la destrucción y la creación son sólo dos aspectos del proceso natural, de forma tal que la acción violenta colectiva puede aparecer tan natural en calidad de prerrequisito de la vida colectiva de la humanidad, como lo es la lucha por la supervivencia y la muerte violenta en la continuidad de la vida dentro del reino animal. ${ }^{11}$

Pero tomando distancia de la estudio de la violencia en el terreno biológico, lo que orbita la compresión de la violencia, eso que nos acecha, en palabras de Arendt, es la muy antigua definición de naturaleza del hombre, la determinación del individuo como animal racional, según la cual el hombre sólo difiere de las otras especies animales en el atributo de la razón.
La violencia como negación: cuando el medio supera al fin que lo justifica

Soy partidario de una política antipolítica, es decir, de una política que no equivalga a una tecnología del poder y la manipulación con él como una forma de dirección cibernética de los hombres o como un arte de finalidades concretas, prácticas o intrigas, sino de la política como una de las formas de buscar y conquistar el sentido de la vida... Sí, la política antipolítica es posible. La política desde abajo. La política del hombre y no del aparato. La política creciente desde el corazón y no de la tesis.

Havel

La acción es el pulso vital para Arendt, es la categoría de la vida y ocupa un lugar central en relación con la reflexión sobre la violencia, a la cual se opone por principio. Lo que hace de un hombre un ser político es su facultad de acción, en tanto ésta le permite unirse a sus iguales para actuar concertadamente y alcanzar objetivos comunes; es la condición de posibilidad de inaugurar algo: lo nuevo. Según la tesis desarrollada en La Condición Humana, actuar sería la respuesta humana a la condición de la natalidad. La llegada del hombre al mundo por virtud del nacimiento, y en tanto recién llegado, debutante en el

11 La engañosa exacerbación de las metáforas orgánicas y biológicas es particularmente peligrosa para el tratamiento de temas donde el elemento biológico está altamente comprometido; el tema del racismo por ejemplo, blanco o negro, está por definición preñado de violencia porque se opone a hechos orgánicos naturales, una piel blanca o negra, que ninguna persuasión ni poder puede modificar; toda solución derivará en el exterminio de sus potadores. 
mundo, le dona la capacidad de comenzar algo nuevo. Sin ese hecho inaugural del nacimiento no tendríamos noticias de la novedad y entonces la acción encontraría límite en su función de preservación, no se diferenciaría de un mero comportamiento, existencia básica. Lo patente es que, a excepción del lenguaje, ninguna otra facultad (razón o conciencia) demarca la radical distinción entre el hombre y todas las demás especies animales. Actuar y comenzar, aunque no equiparables, guardan una íntima relación.

Pero violencia y poder no son fenómenos naturales - en tanto manifestaciones del proceso de la vida-, son propios del terreno político de los asuntos humanos, cuya calidad esencialmente humana está garantizada por la facultad bumana de la acción, la capacidad de comenzar algo nuevo. La tesis arendtiana sobre la violencia se inclina hacia la consideración de que cierta tendencia a la glorificación de la violencia tiene su vórtice en la grave frustración de la facultad de acción en el mundo moderno. La sensación de unidad organizada que producen los actos violentos no permite vislumbrar hasta qué punto estos acontecimientos son el comienzo de algo nuevo, o, como lo afirma Arendt: "los estertores de una facultad que la Humanidad está a punto de perder" (2005, p. 114). Esta dualidad no resuelta de la violencia organizada atenta contra el sentido de la acción, la niega en la medida en que es la creación, la emergencia, la aparición de lo nuevo, de lo novedoso, a lo que debe dar lugar esta facultad. La acción, política siempre, es condición de posibilidad para la aparición del poder. Y si es a través de la acción que es posible la aparición del poder, la violencia también lo niega a éste, lo hace impotente, incapaz de atender su más clara vocación.

El devenir del siglo XX, con el papel que la violencia ha jugado en su construcción, deja al descubierto profundas grietas en la estructura del poder, que se ensanchan y profundizan de la mano de la crisis de las estructuras políticas y de institucionalidad moderna. La crisis del poder, la impotencia del poder, coincide entonces con la crisis de la acción. Y lo nuevo a que debería dar lugar la acción se ha desplazado a los terrenos del desarrollo científico. El poder, con toda su disposición de atender expectativas humanas, ha migrado hacia el desarrollo científico sin resolver la desigualdad a que da lugar. El hombre puede controlar los más complicados procesos tecnológicos aplicados a la prestación de servicios para la atención de necesidades básicas, pero lo ha hecho sin resolver la desigualdad propia del acceso, uso y apropiación a que da lugar el encomio de la técnica. Puede, como considera Arendt, viajar al espacio con menos riesgo del que representa un viaje en metro, pero no puede terminar una guerra sin el aniquilamiento de todas las partes.

Es como si estuviésemos dominados por un hechizo de cuento de hadas que nos permitiera hacer lo imposible a condición de perder la capacidad de hacer lo posible, lograr hazañas fantásticas y extraordinarias con tal de no ser capaces de atender debidamente a nuestras necesidades cotidianas. Si el poder guarda alguna relación con el nosotros-queremos y nosotros-podemos, a diferencia del simple nosotros-podemos, entonces hemos de admitir que nuestro poder se ha tornado impotente (Arendt, 2005, p.118).

Se hace la guerra porque se puede, se es violento porque se puede serlo y esta lógica es profundamente racional, nada emotivo o irracional; nada tiene que ver el juicio, o la valoración y mucho menos la relación con las necesidades cotidianas. Lo que lleva a Arendt a afirmar que toda noción de progreso logrado por la ciencia nada tienen que ver con el yo-quiero; seguirá sus propias leyes inexorables, obligándonos a hacer lo que podemos, prescindiendo de las consecuencias. ¿Puede decirse que todo lo que sabemos, es decir, todo lo que podemos, ha acabado por enfrentarse con lo que somos?

Sólo después de que se deja de reducir los asuntos públicos al tema de la violencia y el dominio, es decir, cuando se supere la negación reforzada por el lenguaje de la violencia, aparecerán, o más bien reaparecerán en su auténtica diversidad las verdaderas condiciones de ser de las relaciones en el terreno de los asuntos humanos. 


\section{Referencias}

Arendt, H. (1973). Crisis de la República. Madrid: Taurus.

. (1993). La Condición Humana. Barcelona: Paidós.

- (1995). De la Historia a la Acción. Barcelona: Paidós.

- (1996). Entre el Pasado y el

Futuro: Península. Barcelona.
(2005). Sobre la Violencia. Madrid: Taurus.

Esquirol, J. at al. (1994). En Torno a Hannah Arendt. Madrid: Centro de Estudios Constitucionales.

Hobbes, T. (1983). Leviatán. Madrid: Nacional.

Weber, M. (1964). Economía y Sociedad. México D.F.: Fondo de Cultura Económica. 